\title{
A report of the first 3 cases of robotic-assisted laparoscopic kidney transplantation in the UK
}

R Uwechue, P Gogalniceanu, I Loukopoulos, B Challacombe, P Dasgupta, J Olsburgh, N Kessaris, P Modi, N Mamode
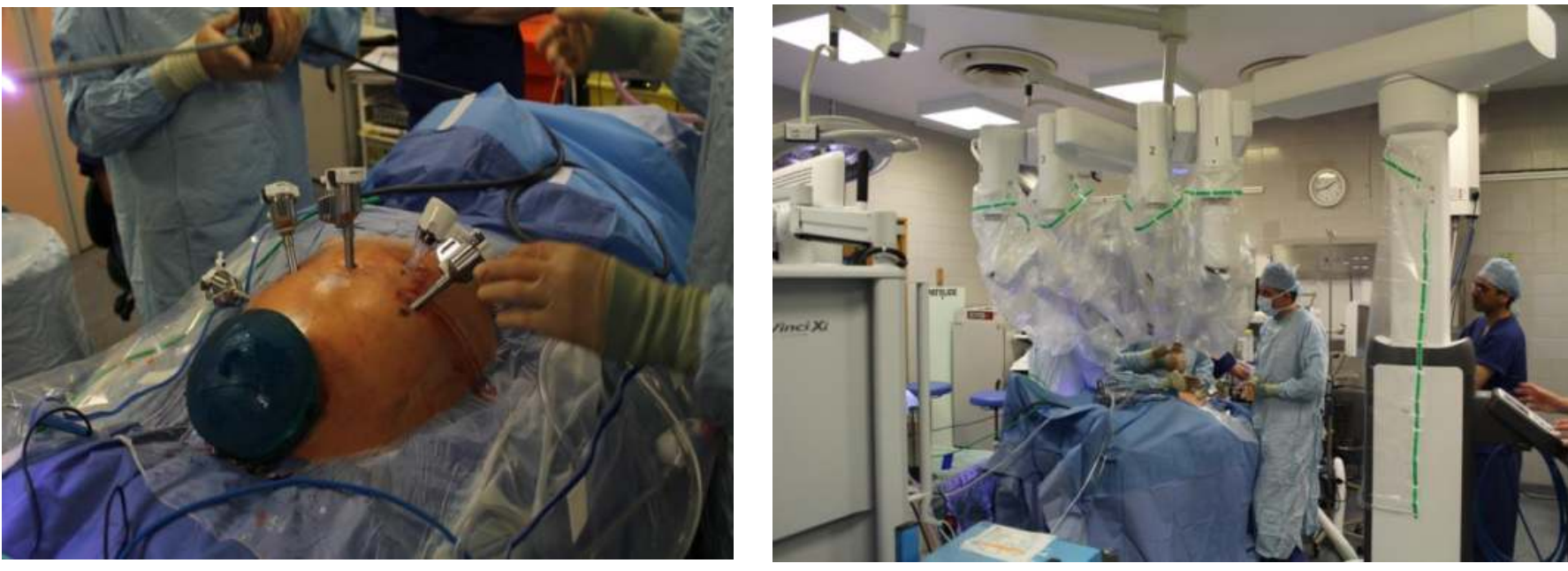

Background

Introduction

- Kidney transplantation is the gold standard treatment for people with End Stage Kidney Disease (ESKD).

- Surgery has traditionally been performed with a large open incision with associated complications.

- Minimally invasive surgery (MIS) is an innovation that has transformed many branches of surgery including transplantation via the laparoscopic donor nephrectomy.

- Robotic assisted laparoscopic surgery is a further evolution of MIS that has significantly enhanced other surgical specialties in the last few years.

- Key benefits of robotic assisted surgery include reduced pain from smaller incisions with faster postoperative recovery for patients and enhanced precision instrument control with highly ergonomic design for the surgeon.

- Robotic assisted kidney transplantation (RAKT) is becoming a standard technique in several centres across the world.

Evolution of the idea at Guy's

- Concept of MIS for kidney implantation conceived in 2007.

- The technique was modelled using animals (pig) and cadavers.

- Training was developed using the robotic simulator at Guy's.

- A close collaboration was developed with Professor Pranjal Modi from the Institute of Kidney Diseases and Research Centre, Ahmedabad, India.

- The first 3 cases of RAKT were performed in late 2016.

\section{Methods}

Clinical details of patients selected for living donor robotic transplantation were recorded. Primary outcome was renal function (eGFR) at one month, secondary outcomes included pain, opiate usage, length of stay and complications. Pain was recorded with a standard 10- point visual analogue scale and analgesia requirement was calculated by converting all opioid used into oral morphine equivalents using standard charts.
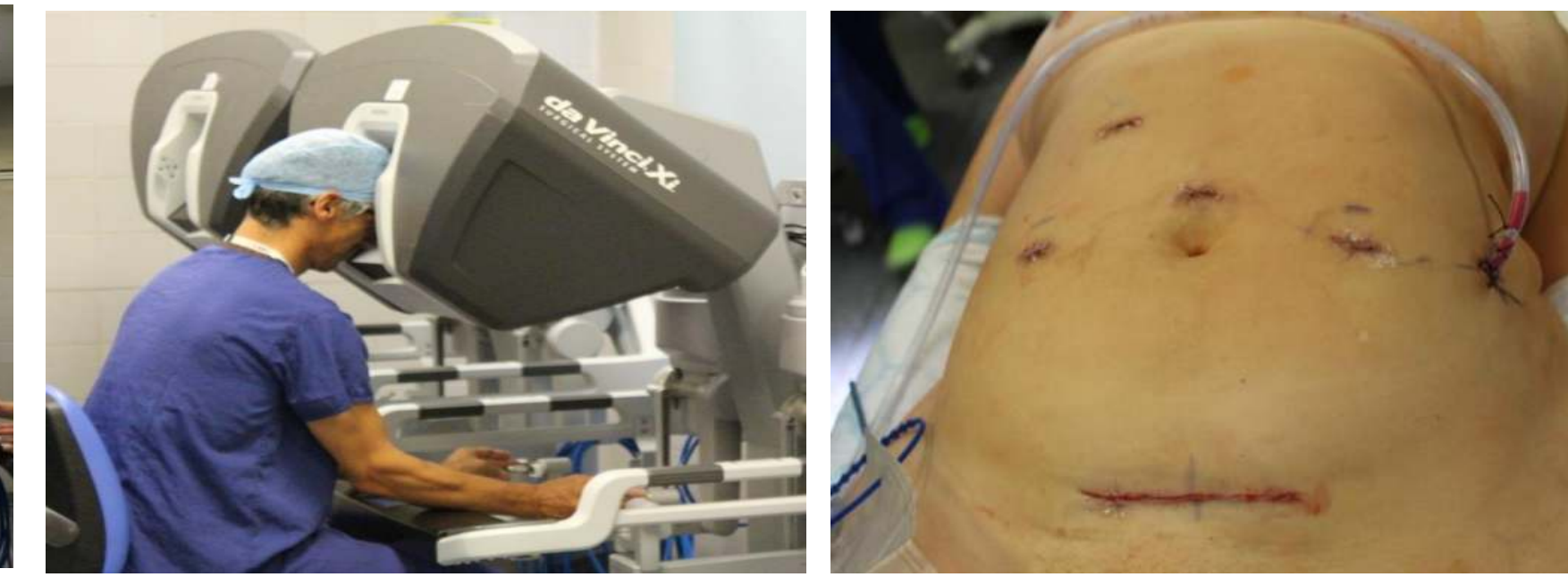

Results

Case 1: 58 year old male with adult polycystic kidney disease and pre-dialysis. He had a BMI of 28 . He had immediate graft function with a creatinine of $104 \mu \mathrm{mol} / \mathrm{L}$ one week after transplantation. He suffered a superficial wound infection within a month of surgery.

Case 2: 42 year old female with anti-GBM disease and a failing first kidney transplant due to infections. She had a BMI of 29. She underwent RAKT to the left side. She had immediate graft function. Her creatinine on the seventh postoperative day was $125 \mu \mathrm{mol} / \mathrm{L}$.

Case 3: 49 year old female with chronic kidney disease from renal calculi who was a pre-emptive transplant. BMI of 26. She had immediate graft function. Her creatinine 1 month after surgery was $95 \mu \mathrm{mol} / \mathrm{L}$.

\begin{tabular}{|c|c|c|c|c|c|c|}
\hline Case & $\begin{array}{l}\text { Rewarm } \\
\text { time } \\
\text { (mins) }\end{array}$ & $\begin{array}{l}\text { eGFR } \\
\text { pre-op }\end{array}$ & $\begin{array}{l}\text { eGFR } 1 \\
\text { Month }\end{array}$ & $\begin{array}{l}\text { Mean pain } \\
\text { score (0-10) }\end{array}$ & $\begin{array}{l}\text { Total } \\
\text { morphine } \\
\text { (ms) }\end{array}$ & $\begin{array}{l}\text { Dischar: } \\
\text { e day }\end{array}$ \\
\hline 1 & 87 & 13 & 65 & 1 & 15 & 4 \\
\hline 2 & 73 & 7 & 42 & 1.5 & 90 & 4 \\
\hline 3 & 78 & 11 & 52 & 2.9 & 26 & 4 \\
\hline
\end{tabular}

\section{Discussion}

- We have demonstrated the applicability and safety of this novel operative technique in the UK.

- These early cases show significant potential in facilitating earlier discharge from hospital with less pain and a potentially superior post-operative recovery phase.

- The effect of the longer rewarming time needs to be evaluated. 